\title{
PARQUE NACIONAL DA SERRA DA CANASTRA: POTENCIALIDADES E FRAGILIDADES
}

\author{
Laís Naiara Gonçalves dos Reis ${ }^{1}$
}

\author{
Cristiane Aparecida Silva Moura de Melo²
}

\begin{abstract}
RESUMO
O Parque Nacional da Serra da Canastra foi criado em 1972 com o objetivo de proteger as nascentes dos mananciais de três bacias hidrográficas (São Francisco, Rio Paranaíba e Rio Grande), com uma área que representa aproximadamente $3,8 \%$ da área protegida de cerrado sob as Unidades de Conservação federais que está localizado à Sudoeste de Minas Gerais, apresentando uma área prevista de 200.000 hectares. A área de estudo abrange os municípios de São Roque de Minas, Vargem Bonita, Delfinópolis, São João Batista do Glório, Capitólio e Sacramento. O Parque da Serra da Canastra possui elevado potencial voltado para o geoturismo, devido à existência de grandes paredões, cachoeiras, formações vegetais distintas e sítios arqueológicos. A área do Parque Nacional da Serra da Canastra apresenta potencialidade especial para a conservação da fauna e flora do Cerrado, pelo tamanho significativo de amostra do bioma. Em relação às fragilidades destacamse:Estrada Principal do Chapadão da Canastra não pavimentada; Linhas de transmissão (Sistema Cemig) atravessando, no sentido longitudinal a Serra da Canastra; intensa atividades Off Road (jipe e motocicleta); invasão por gado; incêndios criminosos e queima não controlada, entre outras.
\end{abstract}

PALAVRAS-CHAVE: Parque Nacional da Serra da Canastra, potencialidades, fragilidades.

\section{NATIONAL PARK SERRA DA CANASTRA: MERITS AND}

\section{WEAKNESSES}

\begin{abstract}
The National Park of Serra da Canastra was created in 1972 with the goal of protecting the headwaters of three watersheds watersheds (San Francisco, Rio Parnaiba and Rio Grande), with an area representing approximately $3.8 \%$ of the protected area of cerrado under the federal Conservation Units which is located to the west of Minas Gerais, with an estimated area of 200,000 hectares. The study area covers the municipalities of São Roque de Minas, Bonita, Delfinópolis, St. John the Baptist glory, Capitol and Sacramento. The Serra da Canastra has high potential facing the geotourism, due to the existence of large cliffs, waterfalls, distinct plant formations and archaeological sites. The area of the Serra da Canastra National Park has special potential for the conservation of fauna and flora of the Cerrado, the significant sample size of the biome. Regarding weaknesses stand out: Main Road Chapadão of unpaved Canastra; Transmission lines (Cemig System) across, lengthwise Serra da Canastra; Off Road intense activities (jeep and motorcycle); invasion by cattle; arson not controlled and burns, among others.
\end{abstract}

\footnotetext{
${ }^{1}$ Doutoranda em Geografia-UFU, Msc. em Geografia -UFU, Técnica de laboratório de Sensoriamento Remoto e Fotogrametria do Instituto de Geografia-UFU. E-mail: laisngr@ufu.br

2 Mestranda em geografia da Universidade Federal de Goiás - Campus Catalão. crisapa3179@gmail.com.br
} 


\section{PARQUE NACIONAL SERRA DA CANASTRA: MÉRITOS Y DEBILIDADES}

\section{RESUMEN}

El Parque Nacional de Serra da Canastra fue creado en 1972 con el objetivo de proteger las cabeceras de tres cuencas cuencas hidrográficas (San Francisco, Río Parnaíba y Río Grande), con una superficie que representa aproximadamente el $3,8 \%$ de la zona protegida de cerrado en las Unidades de Conservación Federal, que se encuentra al oeste de Minas Gerais, con una superficie estimada de 200.000 hectáreas. El área de estudio abarca los municipios de São Roque de Minas, Bonita, Delfinópolis, St. John el Bautista gloria, Capitol y Sacramento. La Serra da Canastra cuenta con un alto potencial de cara al geoturismo, debido a la existencia de grandes acantilados, cascadas, formaciones vegetales distintas y sitios arqueológicos. El área del Parque Nacional Serra da Canastra tiene un potencial especial para la conservación de la fauna y flora del Cerrado, el tamaño de la muestra significativa del bioma. En cuanto a las debilidades destacan: Main Road Chapadão de terracería Canastra; Las líneas de transmisión (Sistema de Cemig) a través de, a lo largo de la Serra da Canastra; Off Road actividades intensas (jeep y moto); invasión por el ganado; incendio no controlado y quemaduras, entre otros.

PALABRAS-CLAVE: Parque Nacional Serra da Canastra, capacidades, debilidades.

\section{INTRODUÇÃO}

Segundo o Instituto Chico Mendes (ICMBIO) a seca de 1971 foi uma das responsáveis para a criação do parque, pois o Rio São Francisco ficou inavegável. Atrelado a essa condição climática, aspectos de uso do solo estavam interferindo no potencial de recarga do lençol dessa Região. Viu-se a necessidade de proteger o Rio São Francisco, em 1972 criou-se o Parque Nacional da Serra da Canastra com o objetivo de proteger as nascentes dos mananciais de três bacias hidrográficas.

A Lei no 9.985 , de 18 de junho de 2000 foi instituída para ordenar as áreas protegidas em níveis Federal, Estadual e Municipal. Esse é um aparato legal importante para o processo conservacionista para as categorias de Unidade de Conservação (UC).

As Unidades de Conservação podem ser separadas como sendo de proteção integral e de uso sustentável. O Instituto Chico Mendes as define da seguinte forma:

- As Unidades de Proteção Integral têm como objetivo básico à preservação da natureza, sendo admitido o uso indireto dos seus 
recursos naturais, com exceção dos casos previstos por Lei. Esse grupo é composto pelas seguintes categorias de manejo: Estação Ecológica, Monumento Natural, Parque Nacional, Refúgio de Vida Silvestre e Reserva Biológica.

- As Unidades de Conservação de Uso Sustentável têm como objetivo básico compatibilizar a conservação da natureza com o uso sustentável de parcela dos seus recursos naturais. Esse grupo é composto pelas seguintes categorias de manejo: Área de Proteção Ambiental, Área de Relevante Interesse Ecológico, Floresta Nacional, Reserva Extrativista, Reserva de Fauna, Reserva de Desenvolvimento Sustentável e Reserva Particular do Patrimônio Natural.

O Parque Nacional da Serra da Canastra representa aproximadamente 3,8\% da área protegida de cerrado sob as Ucs federais.

Dentro do grupo de unidades de proteção integral representa a sexta área mais extensa em superfície protegida, perdendo apenas para Parque Nacional das Nascentes do Rio Parnaíba (729.813,55 ha), Estação Ecológica Serra Geral do Tocantins (716.306 ha), Parque Nacional Araguaia (557.714 ha), Parque Nacional Serra das Confusões, que protege um ecótono de catinga/cerrado (502.411 ha) e Estação Ecológica Jutaí-Solimões (288.187,37 ha). (ICMBIO)

O Parque Nacional da Serra da Canastra localiza-se a Sudoeste de Minas Gerais, apresentando uma área prevista de 200.000 hectares. Abrangendo os municípios de São Roque de Minas, Vargem Bonita, Delfinópolis, São João Batista do Glório, Capitólio e Sacramento. Contudo, somente 71.525 hectares foram desapropriados. Essa porção abrange os municípios de São Roque de Minas, Sacramento e Delfinópolis. (figura 1) O ICMBIO explica as formas de ter acesso ao Parque. (Quadro 1) 
Figura 1. Localização e acesso ao Parque Nacional da Serra da Canastra.

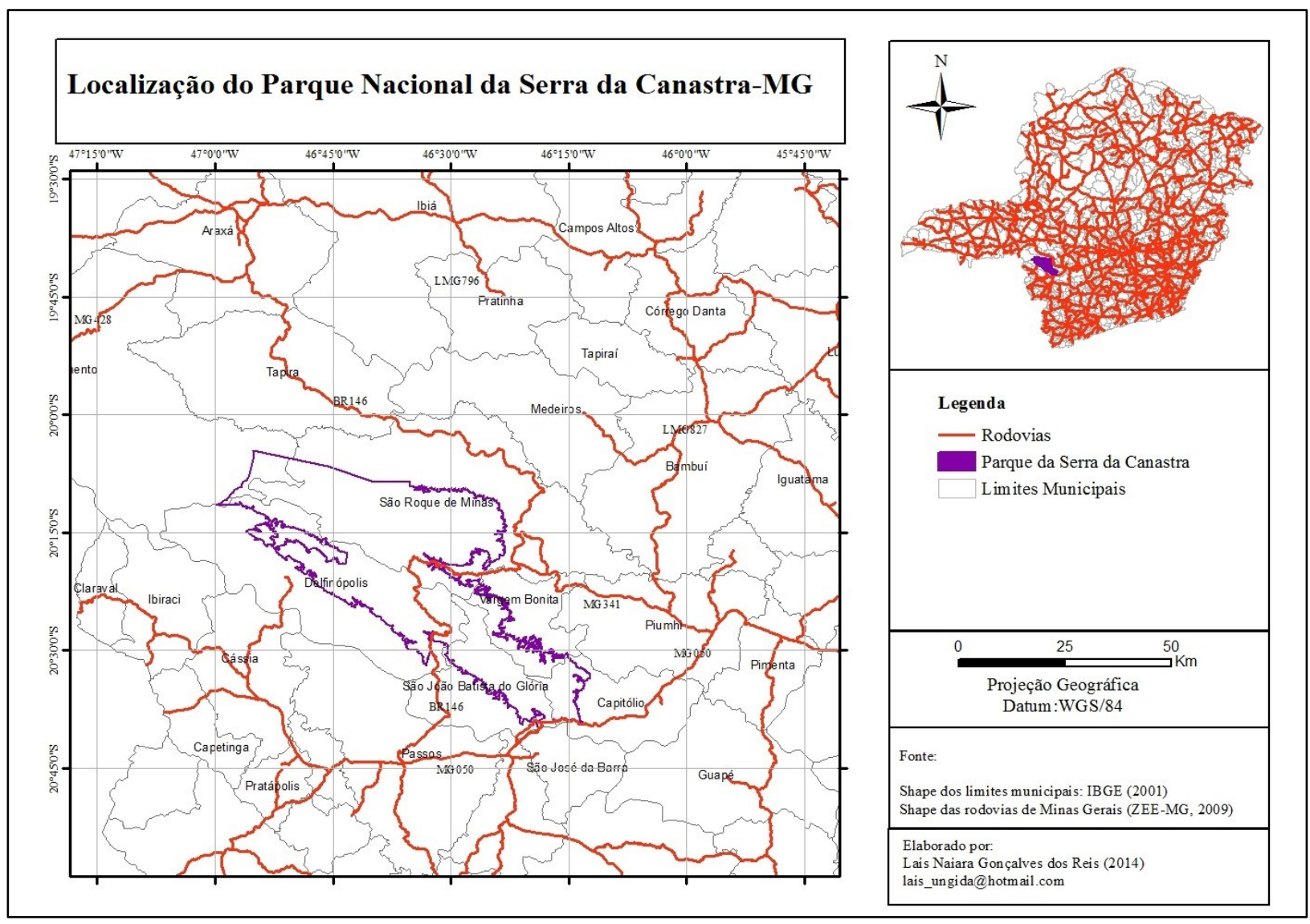

Org. REIS, 2014.

Quadro 1. Como chegar no Parque da Serra da Canastra.

\section{COMO CHEGAR}

Via Aérea: Araxá/MG, a 160 km, e Piumhi/MG, a $70 \mathrm{~km}$ da nascente do São Francisco, são as cidades mais próximas em estrutura aeroportuária.

Via Rodoviária: Belo Horizonte está a $320 \mathrm{~km}$ da nascente,. Saindo da cidade pela BR-381, toma-se a BR-262 sentido Triângulo Mineiro e segue-se a MG-050 até Piumhi/MG. De São Paulo o caminho é por Campinas de onde se acessa Minas Gerais buscando-se a S. S. do Paraíso/MG e Passos/MG. De Passos, cruzando a ponte do rio Grande pode-se entrar na área não regularizada via São João Batista do Glória/MG ou seguir pela rodovia MG-050 até Piumhi/MG e dali para São Roque de Minas (nascente e parte alta da Casca D'anta) e Vargem Bonita (parte baixa da Casca D'anta). Há ainda a possibilidade de entrada em MG via Franca, buscando-se Delfinópolis e acessando o Parque por sua área não regularizada. A rodovia MG-050 é pavimentada e as demais opções são feitas em estradas de terra muitas vezes em estado precário, desaconselhável para veículos que não sejam 4x4.

Fonte: ICMBIO.

\section{DESENVOLVIMENTO}

\section{Observação da paisagem do Parque Nacional da Serra da Canastra}


A Geografia busca entender a paisagem e representá-la de alguma forma. Como forma de apreender a paisagem, o pesquisador precisa observar, experimentar e reproduzir os conceitos apreendidos. Dessa forma, o campo em conjunto com outras informações gráficas permite complementar o discurso dedutivo e indutivo dessa Ciência. E ainda estabelecer conexão com as teorias e discussões da sala de aula, incrementando o processo de cognição.

Nesta perspectiva, é de fundamental importância que o pesquisador em Geografia tenha clareza do método de pesquisa. Em específico na subdivisão de pesquisa em Geografia Física, Sposito (2004) seleciona alguns métodos de pesquisa:hipotético-dedutivo, onde a paisagem será descrita por meio de hipóteses e deduções, o dialético, em que se busca a compreensão da relação homem-meio e a marca disso no espaço e o fenomenológico-hermeneutico que é a descrição do objeto de estudo por meio do sujeito (sensações). De acordo com cada método escolhido para análise em Geografia, muda-se o tratamento em lócus, ou seja, no campo, quais os procedimentos técnicos que devem ser abordados, por exemplo. Mas, é de senso comum que para qualquer método de pesquisa em Geografia, o papel relevante do campo para obtenção de informações sobre qualquer objeto de estudo na ciência geográfica.

Salienta-se ainda, a intimidade do Geógrafo com o campo, para apreender o seu objeto de estudo e a capacidade de integrar os elementos da paisagem para construir um pensamento de funcionalidade da mesma. Essa potencialidade é diferenciada em relação aos demais profissionais em Geociências, por exemplo.

O Parque Nacional da Serra da Canastra esta inserido no Bioma Cerrado que historicamente foi devastado pelos agentes transformadores do espaço, em função do incentivo de políticas públicas que incentivaram a modernização agrícola e desenvolvimento urbano nessa região, uma vez que as formações desse Bioma foram menosprezadas em relação aos demais Biomas brasileiros, em função da aparência do cerrado sentido restrito, com árvores baixas, de cascas grossas e troncos retorcidos. 
Para SOUZA et al. " as flores do Cerrado apresentam-se singelas e pequenas, por isso, frágeis e sujeitas aos não olhares; massacradas por manejos e ceifadas por mudanças, por isso, submetidas aos insensíveis, escondidas e excluídas, por isso sob jugo aos desatentos". A foto 1 mostra uma flor do campo de altitude do Parque Nacional da Serra da Canastra, uma espécie arbustiva que evidencia essa característica de fragilidade e singeleza trazida pelos autores. Por outro lado, a cor lilás das pétalas quebra a paisagem de cor "pálida" do outono dos campos de altitude da Serra da Canastra.

Foto 1. Espécie arbustiva da formação de campo de altitude da Serra da Canastra.

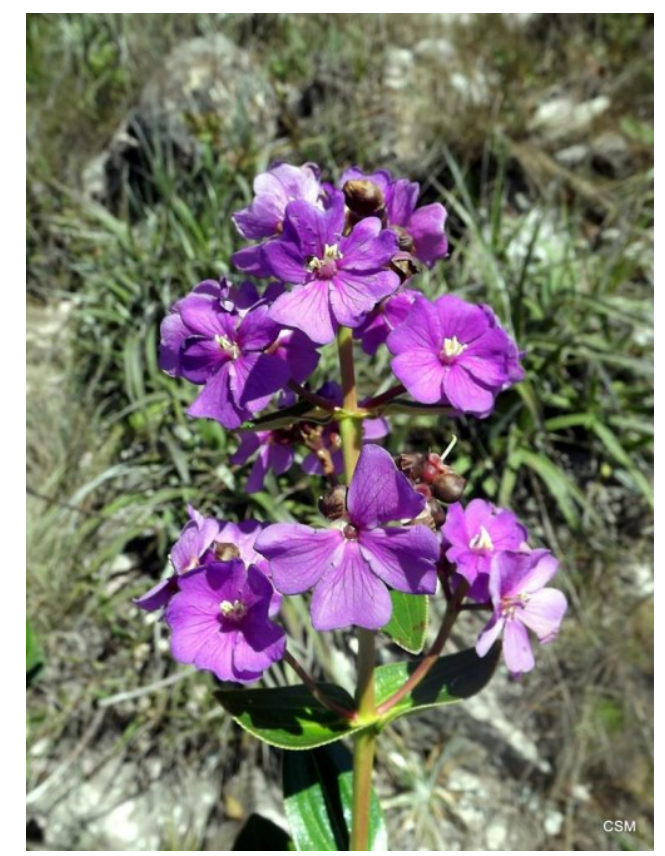

Autora: Magalhães, 2014.

A formação mais abrangente do Bioma Cerrado é o cerrado stricto sensu, segundo EITEN (1972); RIBEIRO; WALTER (1998) essa fitofisionomia representa cerca de $70 \%$ do Bioma. As outras formações são variações do cerradão, campos úmidos, campos de altitude e matas.

A Serra da Canastra-MG é um divisor de águas de três bacias: baixo Paranaíba, Alto São Francisco e Rio Grande. (Figura 02) 
Figura 2. Bacias hidrográficas: Parque Nacional da Serra da Canastra.

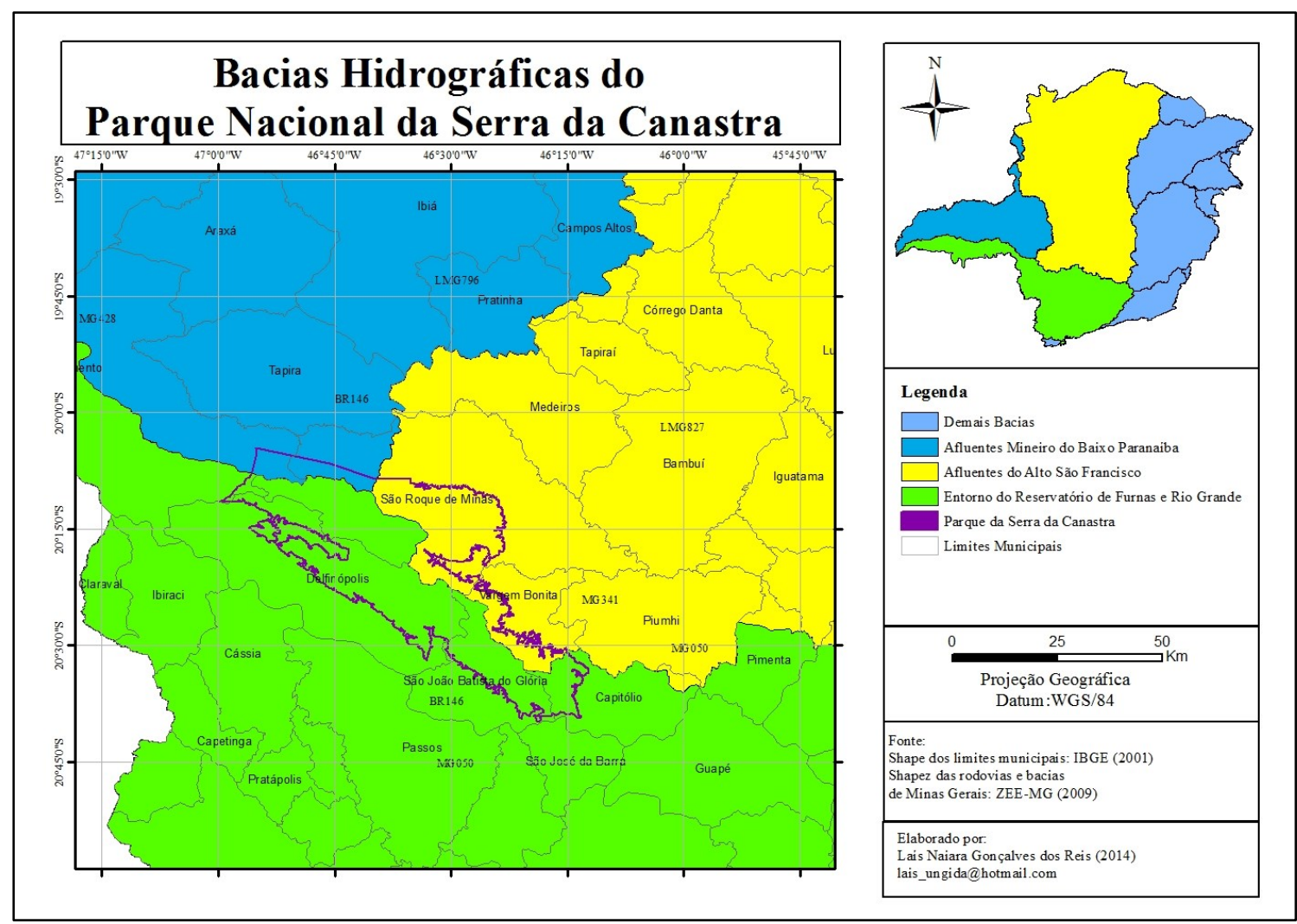

Org. REIS, 2014.

O Parque da Serra da Canastra possui elevado potencial voltado para o geoturismo, devido à existência de grandes paredões, cachoeiras, formações vegetais distintas e sítios arqueológicos. Esse potencial não é explorado, em campo não foi detectada nenhuma placa explicativa sobre as características físicas (geomorfologia, geologia, biogeografia, etc.) das áreas do Parque. Não foi percebida nenhuma trilha orientada para guiar os turistas e nem um controle eficiente para evitar que os mesmos adentrem em áreas que sirvam de refúgio silvestre. Isso demonstra a falta ou ineficiência de um plano de manejo do Parque. Os pontos mais procurados pelos turistas são a nascente do rio São Francisco, a parte alta da cachoeira Casca D'anta (foto 2) e sua parte baixa. A parte alta da Casca D'anta apresenta piscinas naturais, bastante frequentadas pelos turistas (foto3). 


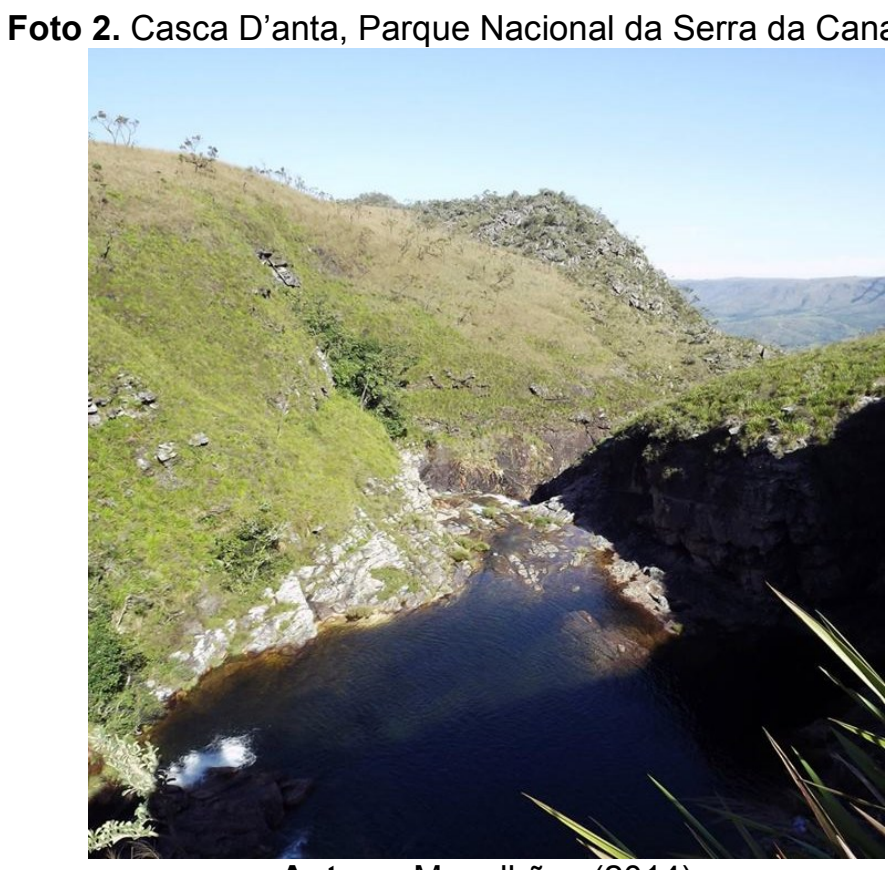

Autora: Magalhães (2014)

Foto 3. Piscinas naturais da parte alta da Casca D'anta, Parque Nacional da Serra da Canastra.

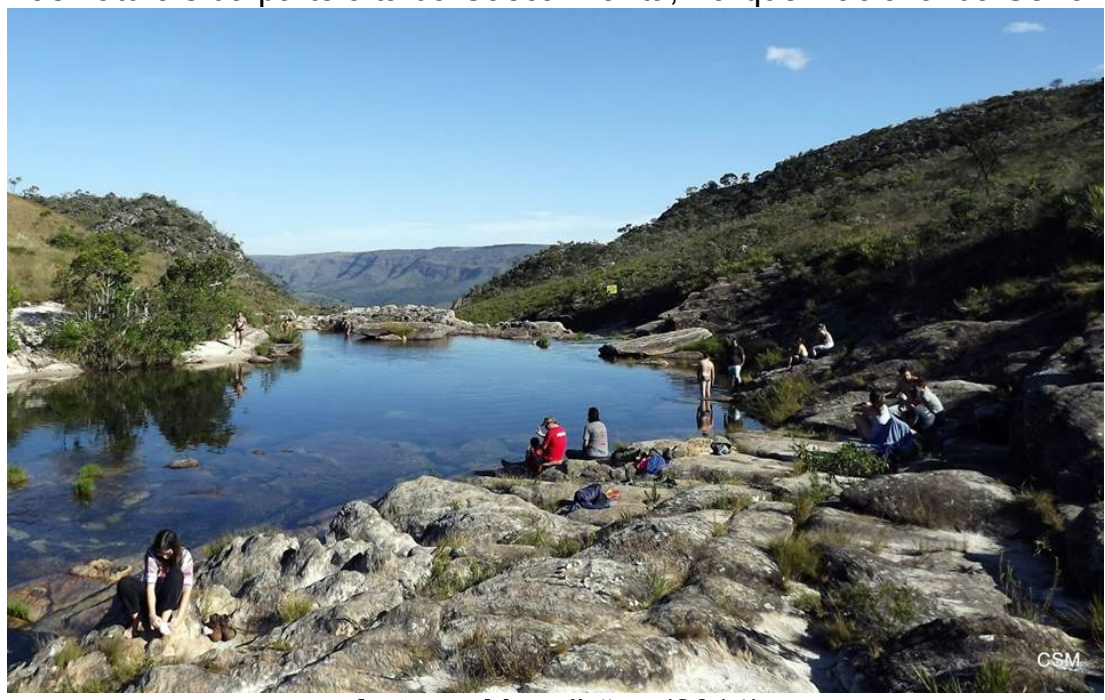

Autora: Magalhães (2014)

Na paisagem do Parque Nacional da Serra da Canastra também é possível perceber a influencia da religiosidade, uma vez que para ilustrar a nascente do rio São Francisco, há a imagem de um santo da Igreja Católica Apostólica Romana, São Francisco de Assis (Foto 4). Para Rosendahl (1996), a paisagem e uma dimensão morfológica, ou seja, é um conjunto de formas criadas pela natureza e ação humana, portanto é portadora de significados: valores, crenças, mitos e utopias. Assim, a paisagem é também dotada de dimensão simbólica. A localização simbólica da 
nascente do rio São Francisco é devido às cabeceiras de drenagem em anfiteatro, essas constituem unidades fundamentais de evolução do relevo no Quaternário tardio.

Foto 4. São Francisco de Assis, Parque Nacional da Serra da Canastra.

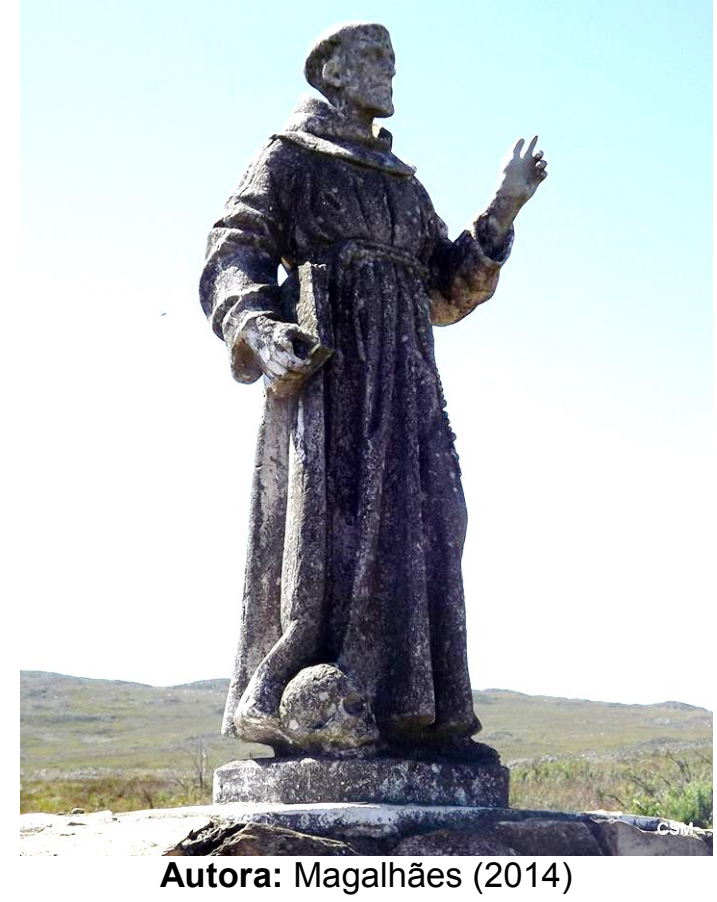

A área do Parque Nacional da Serra da Canastra é considerada especial para a conservação da fauna e flora do Cerrado, pelo tamanho significativo de amostra do bioma com cerca de 70 hectares, onde a região apresenta áreas com alta à elevada a extrema necessidade de conservação, segundo o Biodiversitas. (figuras 4 e 5)

O estabelecimento dessa UC é uma importante estratégia para garantir às gerações futuras acesso aos bens materiais e imateriais proporcionados por esse espaço. Sendo assim, é fundamental um plano de manejo para o Parque Nacional da Serra da Canastra, bem como para a área de amortecimento que equivale $10 \mathrm{~km}$.

$\mathrm{Na}$ área de amortecimento e no Parque Nacional da Serra da Canastra podem ser destacado algumas fragilidades que ameaçam o propósito da área de conservação da fauna e da flora do Cerrado, tais como: 
1. Estrada Principal do Chapadão da Canastra não pavimentada, perfazendo um total de aproximadamente $67 \mathrm{~km}$, com trânsito livre de veículo, inclusive carga;

2. Linhas de transmissão (Sistema Cemig) atravessando, no sentido longitudinal a Serra da Canastra;

3. Atividades Off Road (jipe e motocicleta);

4. Invasão por gado;

5. Incêndios criminosos e queima não controlada.

6. Supressão da vegetação nativa e substituição por SSP. exóticas.

7. Atividades no Chapadão da Babilônia (só podem ser paralisadas quando da indenização das propriedades/posses)

8. Atividades agropecuárias, com uso de insumos agroquímicos sintéticos e manejo inadequado do solo;

9. Atividades silviculturais com espécies Exóticas

10. Excesso de estradas e acesso livre às áreas não indenizadas;

11. Exploração de quartzito (pedra mineira) e alvará de pesquisa para exploração de diamante;

12. Atividades turísticas sem planejamento e controle.

As fotos 5, 6 e 7 mostram alguns usos variados na área de amortecimento do Parque Nacional da Serra da Canastra.

Foto 5. Lavoura de milho na área de amortecimento do Parque Nacional da Serra da Canastra-MG.

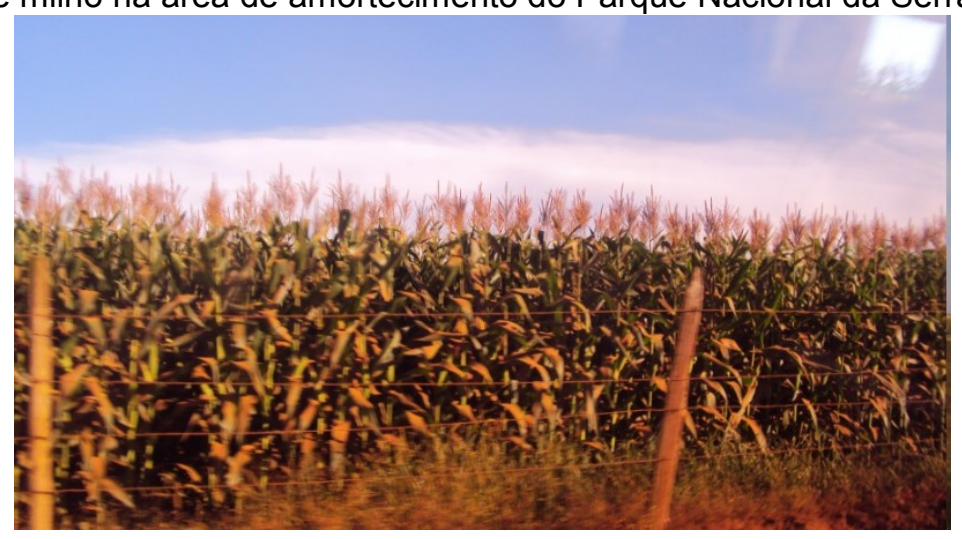

Autor: Silva (2014) 
Foto 6. Áreas de extração de minério e pastagem na área de amortecimento do Parque Nacional da Serra da Canastra.

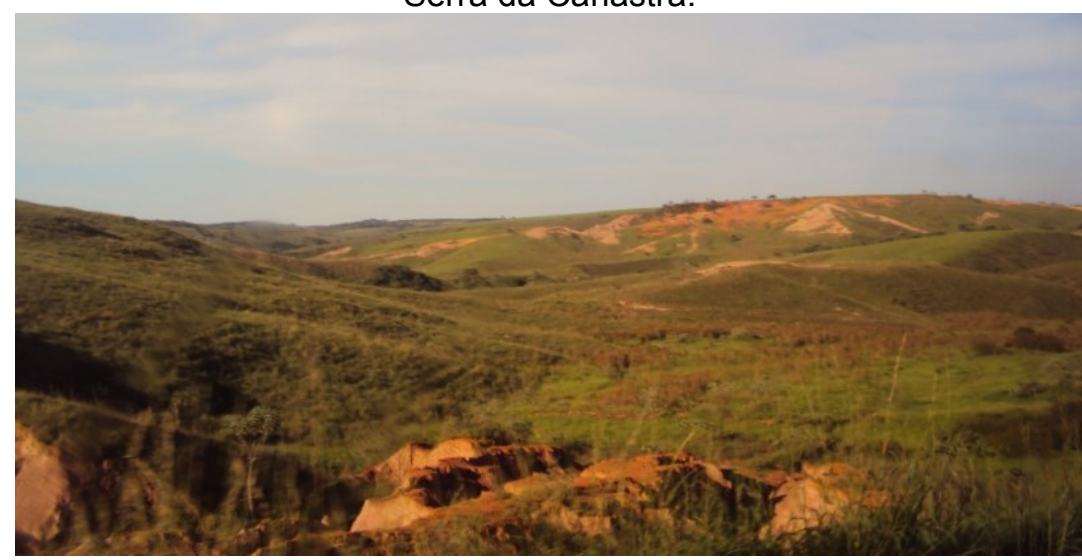

Autor: Silva (2014)

Foto 7. Áreas de pastagens e silvicultura na região de amortecimento do Parque Nacional da Serra da Canastra.

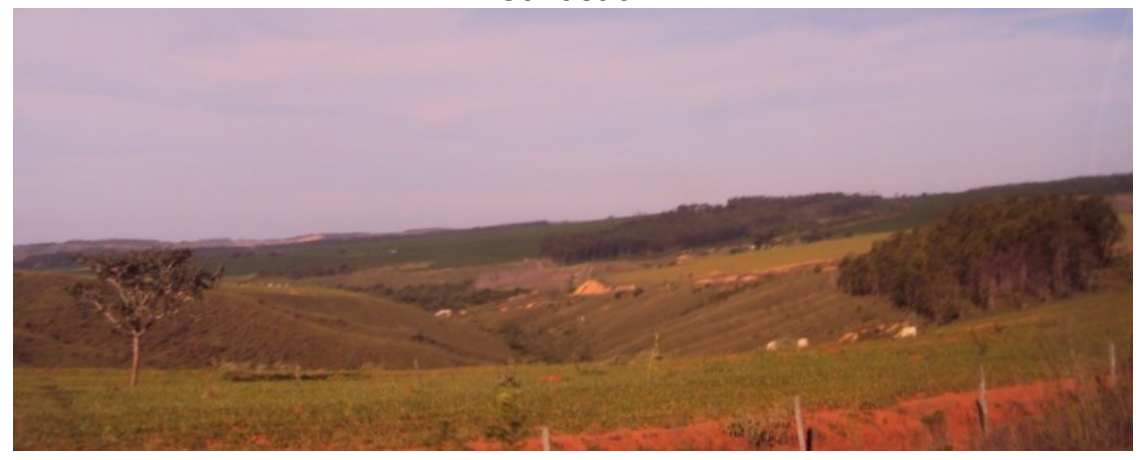

Autor: Silva (2014)

O zoneamento ecológico e econômico de Minas Gerais (ZEE-MG) apresenta alguns dados de susceptibilidade e fragilidade da área de estudo em função das características física do Parque Nacional da Serra da Canastra e entorno. Com base nesse banco de dados foram elaborados os mapas de áreas prioritárias de conservação da fauna( figura 4), da flora (figura 5). 
Figura 4. Mapa das áreas prioritárias para conservação da fauna na região do Parque Nacional da Serra da Canastra.

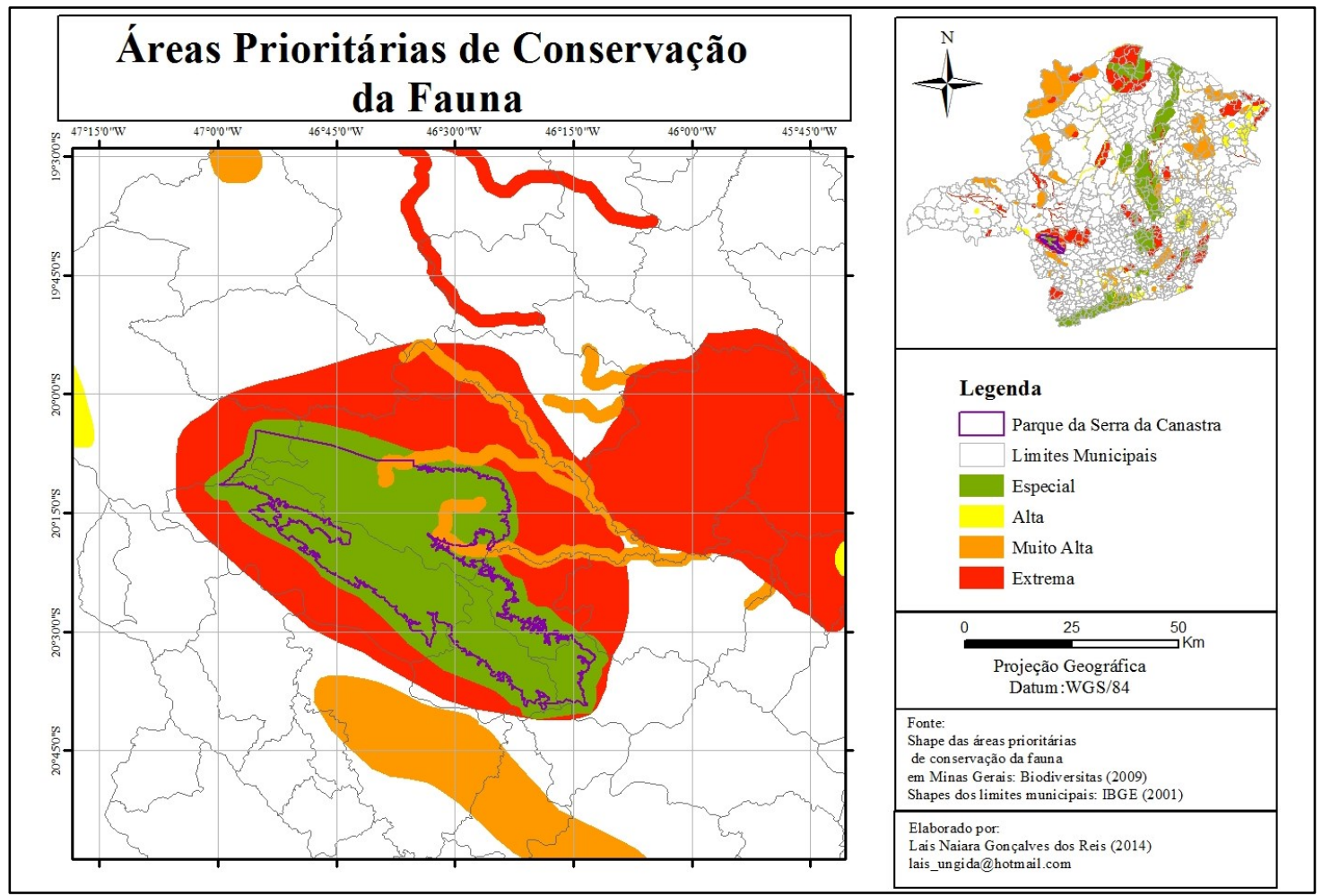

Org. Reis, 2014.

Figura 5. Mapa das áreas prioritárias para conservação da flora na região do Parque Nacional da Serra da Canastra.

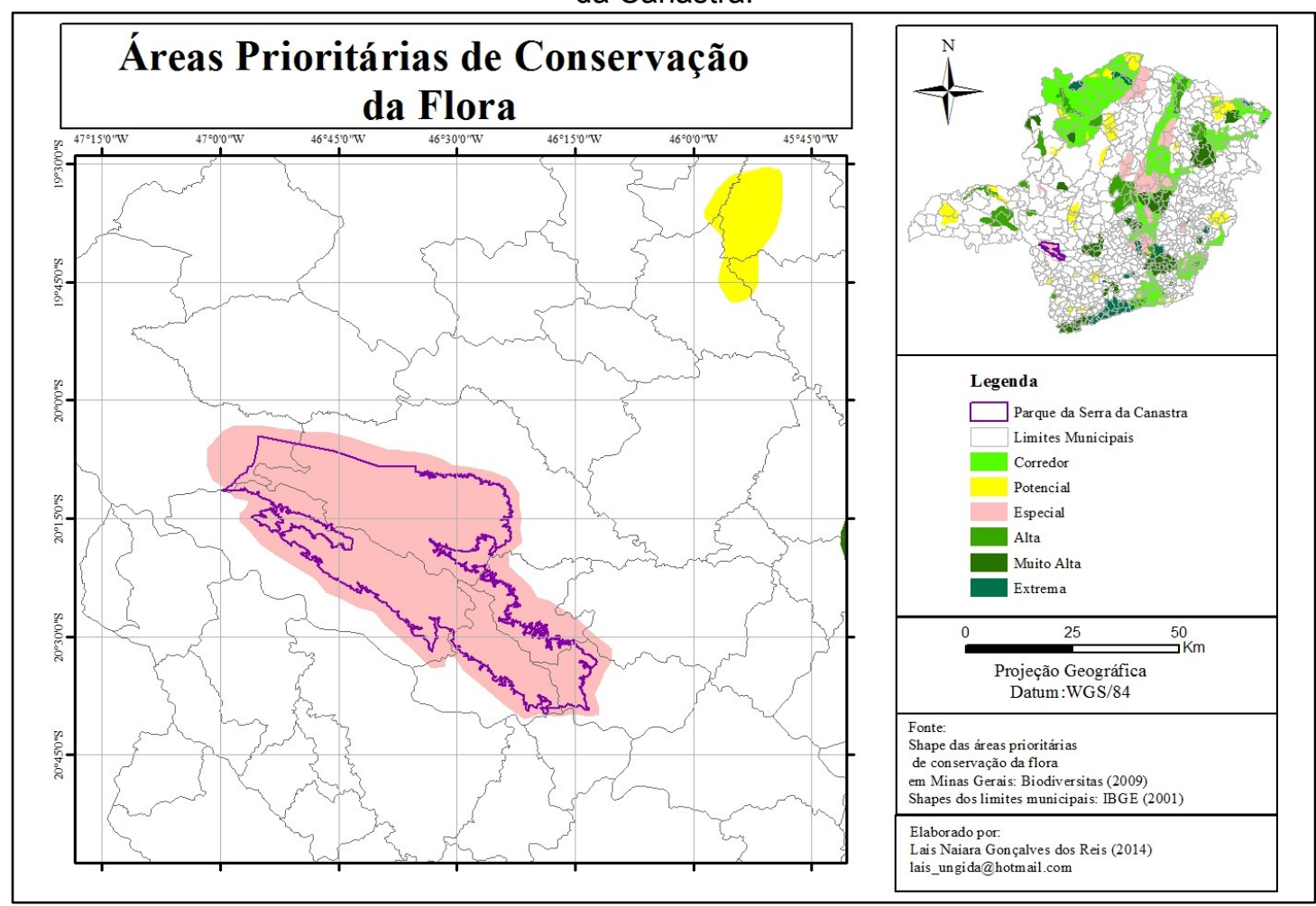

Org. Reis, 2014. 
Como já foi dito nesse relatório, o Parque Nacional da Serra da Canastra PNSC é uma importante área para conservação da flora e da fauna do Cerrado para a região. O ZEE-MG apresenta essa região como sendo uma área especial e entorno de extrema importância como sendo áreas prioritárias para conservação. O ICMbio lista algumas espécies ameaçadas que podem ser encontradas no Parque: GalitoAlectrurus tricolor, Papagaio-de-peito-roxo , Amazona vinacea, Gato-do-matoLeopardus tigrinus, Gato-do-mato-Leopardus tigrinus, Tico-tico-do-mato Coryphaspiza melanotis, Gato-maracajá - Leopardus pardalis mitis, Gato-palheiro Leopardus colocolo, Pato Mergulhão - Mergus octosetaceus, Tamanduá-bandeira Myrmecophaga tridactyla, Codorna-buraqueira - Nothura minor, Perereca-defolhagem-com-perna-reticulada - Phyllomedusa ayeaye, Tatu-canastra - Priodontes maximus, Onça-parda - Puma concolor capricornensis, Inhambu-carapé - Taoniscus nanus.

Quase toda a área do PNSC está caracterizada como sendo de baixa capacidade de mineralização da matéria orgânica. Um dos fatores que explica tal enquadramento refere-se a baixa quantidade de biomassa disponível em função da rala cobertura vegetal, por se tratar de grandes áreas de campo rupestre, em decorrência da altitude, solos rasos e até mesmo locais com afloramento rochoso. Toda a área é considerada como alta suscetibilidade a compactação dos solos.

Devido à ocorrência de afloramentos rochosos em conjunto com solos poucos espessos (litólicos) e baixa cobertura vegetal, a maioria do PNSC foi enquadrado como tendo média a alta suscetibilidade de perda de solo por erosão laminar, entre outros processos.

Por fim, por se tratar de uma área de conservação ambiental, as nascentes encontram-se protegidas ao antigo uso da área, portanto a região apresenta uma baixa suscetibilidade para os recursos hídricos.

\section{CONCLUSÃO}

O plano de manejo é uma importante ferramenta para cumprir o propósito de conservação da biodiversidade nas UC's. O Parque Nacional da Serra da Canastra apresenta um potencial elevado voltado para o Geoturismo, retificando a importância de um planejamento eficiente para que as visitações indevidas e outros usos e 
ocupações dentro e ao entorno do parque não se configurem enquanto fragilidade para essa área. Ainda destaca-se a falta de infraestrutura para o turista para que o Parque possa oferecer atrativo á novos visitantes e para que eles possam retornar à esse ambiente.

Outras questões importantes relacionadas à fragilidade do Parque Nacional da Serra da Canastra é a necessidade de efetiva desapropriação das terras para expandir a área de conservação do parque, falta de fiscalização dentro do mesmo e ao entorno, número insuficiente de profissionais que atuem diretamente no Parque para educação ambiental e orientação aos turistas para evitar o acesso em locais restritos.

Em visitação ao Parque Nacional da Serra da Canastra em maio de 2014 foi possível destacar as fragilidades elencadas neste trabalho, por meio deste estudo orienta-se elaborar um outro para entender o plano de manejo do Parque bem como o zoneamento dessa UC, para verificar se estão de acordo com as potencialidades e fragilidades do mesmo.

\section{REFERÊNCIAS}

BIODIVERSITAS. Atlas da biodiversidade. Diponível em :< http://www.biodiversitas.org.br/atlas/> Acessado em junho de 2014.

BRASIL. LEI. N 9.985, de 18 de junho de 2000. Disponível em :< http://www.planalto.gov.br/ccivil_03/leis/19985.htm> Acesso em junho de 2014.

CASSETI, V. \& NASCIMENTO, M.A.L.S. A importância da geomorfologia nos estudos de risco urbano: o caso de Goiânia. Anais do IV Simpósio de Geografia Física Aplicada, Porto Alegre, p. 37481, 1991.

CHAVEIRO, Eguimar Felício; CASTILHO, Denis. Cerrado: patrimônio genético, cultural e simbólico. In: Revista Mirante, vol. 2, n.1. Pires do Rio - GO: UEG, 2007.

EITEN, G.1972. The cerrado vegetation of Brazil. Botanical. Review, v.38, n. 2, p.201-341.

ICMBIO. Plano de manejo do Parque Nacional da Serra da Canastra. Disponível em:< http://www.icmbio.gov.br/portal/images/stories/imgs-unidadescoservacao/PM_PNSC_Resumo_Executivo.PDF > Acessado em junho de 2014.

RIBEIRO, J.F.; WALTER, B.M.T. Fitofisionomias do bioma Cerrado. IN: SANO, S.M.; ALMEIDA, S.P (ed). Cerrado: ambiente e flora. Brasília, Embrapa Cerrados, 1998. p. 87-166.

ROSENDAHL, Z. Espaço e religião: uma abordagem geográfica. Rio de Janeiro: UERJ, NEPEC. 
SOUZA et al. As flores do Cerrado brasileiro e suas identidades: vida e trajetória de um povo. Disponível em:< http://www.eng2012.org.br/trabalhos-completos?download=230:as-flores-do-cerradobrasileiro-e-suas-identidades-vida-e-trajetoria-de-um-povo\&start=1720.> Acessado em junho de 2014.

SPOSITO. Geografia e filosofia: contribuição para o ensino do pensamento geográfico. São Paulo: Editora UNESP, 2004

ZEE-MG. Informações geoambientais de Minas Gerais.In: Zoneamento Ecológico e Econômico. Disponível:< http://www.zee.mg.gov.br/> Acessado em junho de 2014. 